Questioning the clause as a crosslinguistic unit in grammar and interaction

\author{
Laury, Ritva
}

2019

Laury , R , Ono , T \& Suzuki , R 2019 , ' Questioning the clause as a crosslinguistic unit in grammar and interaction ' , Studies in Language , vol. 43 , no. 2 , pp. 364-401 . https://doi.org/10.1075/sl.17032.lau

http://hdl.handle.net/10138/326006

https://doi.org/10.1075/sl.17032.lau

unspecified

acceptedVersion

Downloaded from Helda, University of Helsinki institutional repository.

This is an electronic reprint of the original article.

This reprint may differ from the original in pagination and typographic detail.

Please cite the original version. 


\title{
Questioning the clause as a crosslinguistic unit in grammar and interaction $^{1}$
}

\author{
Ritva Laury (University of Helsinki), Tsuyoshi Ono (University of Alberta), \\ and Ryoko Suzuki (Keio University)
}

\section{Introduction}

The present contribution explores the 'clause', a most, if not the most, celebrated syntactic unit in linguistics which captures the relationship among units such as phrases, words and affixes. The following quotes illustrate how the 'clause', called S (from 'sentence') in a dominant school of linguistics (e.g., Fromkin et al. 2011), has been understood in structural terms in standard references in linguistics:

A unit of grammatical organization smaller than a sentence, but larger than phrases, words or morphemes (Crystal 1998)

A part of a sentence whose structure is itself like that of a sentence. Thus, in particular, one which includes a verb and elements that can or must accompany it. In older treatments one clause was described as following another; e.g. in I said I saw her, a main clause I said would be followed by a subordinate clause I saw her. As now defined, the main clause is the sentence as a whole and the subordinate clause is said to be included in it: thus, with brackets around each, [I said [I saw her]]. Clauses are distinguished in most accounts from phrases, by criteria which may vary, however, from one to another. (Matthews 2014)

While the first quote defines the clause in terms of its size, compared to other structural units, the second quote above, besides suggesting that clauses can be embedded in sentences, or other clauses, describes another aspect of this unit by specifying what it is composed of: a verb and its accompanying elements. This is also seen in a similar statement found in the following quote where an inclusion of a particular accompanying element is highlighted:

A grammatical unit containing a subject and a predicate (Trask 1997)

\footnotetext{
1 This article is based on a presentation given at the workshop 'Linguistic and interactional units in everyday speech', University of Alberta, Edmonton, Canada, 2013. We would like to thank the workshop participants for their comments and suggestions, and especially Sandy Thompson for planting in us the habit of checking received ideas about language against what actual speakers do, and for always being willing to listen to our 'crazy' ideas. We acknowledge the support from the Social Sciences and Humanities Research Council (435-2013-2185), and the Academy of Finland and the Japan Society for the Promotion of Science for the joint funding of the project "The question of units in language and interaction" (275144). Our research was also partially funded by the Finnish Center of Excellence in Intersubjectivity in Interaction and the Japan Society for the Promotion of Science Grant-in-Aid (17KT0061). The authorship is shared equally.
} 
In addition, some authors suggest a semantic basis for this unit:

The clause is the linguistic expression of a proposition; a proposition is a conceptual notion, whereas a clause is its morphosyntactic instantiation. (Payne 1997: 71; cf. Givón 1984)

The general idea in standard references in linguistics is thus that a predicate (or even a verb) with its accompanying elements constitute a clause, a structural unit, which is understood to instantiate a proposition, a semantic unit.

It seems fair to say that the clause is more or less (often tacitly, without critical examination) accepted as a universal type of structural unit, as it is employed by researchers with different theoretical persuasions in talking about both individual languages and language in general (e.g., Chafe 1994, Chomsky 1957, Comrie 1989, Croft 1990, Greenberg 1978, Shopen 2007, and Thompson and Couper-Kuhlen 2005).

It should be pointed out, however, that illustrating the clause in these references is typically done using English examples (sometimes examples from other European languages) as seen above in the quote from Matthews (2014). This practice is perhaps not surprising considering that English has been the most common form of communication in various areas and fields focused on language, most notably linguistics, for the past several decades.

It should be noted further that the definition of the clause commonly found in general linguistics references is actually very similar to how the English clause is characterized in reference works specifically dealing with English, such as the following:

A clause is a unit structured around a verb phrase. (...) The verb phrase is accompanied by one or more elements which denote the participants involved in the action, state etc., (...) the attitude of the speaker/ writer (...), the relationship of the clause to the surrounding structures, etc. (Biber et al. 1999: 120).

This similarity is very likely due to the fact that much of our current ideas about language have built based on the study of (typically constructed) examples of English and perhaps other European languages. That is, we think this focus on English has led to our current understanding of clause as a universal category.

It is interesting to find researchers who have a particular interest in crosslinguistic variation and actual language use exhibit a similar understanding of clause:

Ordinary discourse does not consist of isolated, context-free utterances, but of linked discourse units comprising reports, orders, comments, descriptions, and other kinds of linguistic activity. These units, usually expressed by clauses, typically consist of a verb and indicators of the 
arguments of the verb, in the form of lexical nouns, pronouns, or pronominal affixes (Hopper and Traugott 2003: 175, emphasis added).

In this study, we take a crosslinguistic approach by examining Finnish and Japanese, two languages which are genetically and typologically distinct from each other and from English, in order to see whether the unit clause, typically assumed to be universal, should be considered a part of the grammar in the two languages. We will do this in two stages.

First, we examine how the clause is defined and discussed in the grammars of Finnish and Japanese. Is the theoretical status of the clause, structurally defined as a predicate with its accompanying elements, perhaps as an outcome of the heavy influence from English (and other European languages), actually relevant for the grammatical description of the languages we study? Or do we need to redefine or even abandon the clause as a crosslinguistically valid unit (cf. Haspelmath 2010a, Ford, Fox \& Thompson 2013; see also Ewing, this issue, Thompson, this issue)?

Second, we examine the clause in Finnish and Japanese everyday conversation through both qualitative and quantitative analysis. Our focus on everyday conversation is deliberate; it is the primary form of language (e.g., Schegloff 1996), yet our current understanding of language in general is known to be heavily influenced by the traditional focus on written language (Linell 2005). We ask whether the 'clause', defined based on mostly constructed examples in standard reference grammars, is found in actual language use, everyday conversation in particular? We give special attention to 'participant orientation', a criterion which has recently been adopted to assess the reality of linguistic structure in interactional linguistics (see, e.g., Thompson and Couper-Kuhlen 2005), to see if the clause is oriented to by participants of Finnish and Japanese conversations.

Our discussion will highlight a number of issues in dealing with the notion of the linguistic unit in general and the clause in particular, a concern shared by other contributions in the volume. By doing this exploration, we hope to come closer to understanding the reality of the clause as a potential universal category and its relevance for individual languages. In the last section, we will present our current understanding of the clause in our attempt to make sense out of some of the representative utterance types found in several genetically, typologically, and geographically diverse languages, English, Finnish, German, Indonesian,

\footnotetext{
2 In a recent paper (2010a), Haspelmath distinguishes descriptive categories and comparative concepts, where the former involve actual categories found in individual languages and the latter, theoretical concepts devised for the purpose of comparing languages. We tend to agree with his distinction, yet a standard practice in various approaches in language typology and linguistic universals has been to use categories (e.g., 'clause') found in individual languages as the data source for actual comparison. In this paper, we approach the structural unit 'clause' through actual language use, examining its validity for Finnish and Japanese, in contrast to many approaches in contemporary linguistics where its reality in individual languages has simply been assumed.
} 
Japanese, and Nuuchahnulth (Wakashan). We question the central theoretical status given to the syntactic unit clause in languages where predicates and their accompanying elements are rarely expressed together. Similarly, to the extent that accompanying elements need not be expressed overtly as found in some languages, we suggest that the syntactic unit clause in those languages is not as grammaticized as it is in languages like English.

\section{Understandings of similar units in standard references in Finnish and Japanese}

\subsection{Finnish}

The clause has been a central concept in Finnish grammars beginning from the first syntactic accounts of the language. In the grammars from the late 19th and early 20th century (Jahnsson 1871: 5; Setälä 19263: 9), the description of Finnish syntax is built around the concept of the clause. The defining property of the clause is taken to be the finiteness of the verb. Thus, in the very beginning of his grammar, Setälä states that "The clause is the linguistic expression of a thought. A complete clause expresses with a finite verb an action, a state, or a property of some object (1926: 9)."4

Early Finnish grammarians (since Setälä 1926: 9) kept apart the concept of lause ${ }^{5}$ 'clause', which had only one finite verb, and virke 'sentence; clause combination', which could consist of one or more clauses. However, later grammarians, most specifically Hakulinen \& Karlsson (1979: 65), citing especially Tuomikoski (1969), suggested that the distinction between virke and lause was not really needed in the study of syntax, since subordinate clauses in a complex sentence are embedded in the main clause as its arguments or modifiers and thus constitute parts of the main clause ${ }^{6}$ (cf. Matthews 2014, quoted above). In such an approach, lause then would approach the meaning of S(entence)in autonomous grammar. However, Hakulinen and Karlsson (65) also note that compound sentences need their own term (lauseliitto 'clause union'), since coordinated clauses by definition do not have a syntactic role in the other clause. They also saw a need for another term for combinations of clauses joined with connectors other than conjunctions (e.g. lisäksi 'in addition', and other such elements which can also combine units of discourse larger than the clause, differently from conjunctions, which combine clauses and phrases), for which the term virke 'sentence' was retained.Thus Hakulinen and Karlsson (1979) end up with three terms, lause, which stands for both simple and complex clauses, lauseliitto, for coordinated clause combinations, and virke for combinations of

\footnotetext{
3 Setälä's 1926 grammar is a modified version of the Finnish grammar he wrote as a 16year-old schoolboy in 1880. That grammar was based on Jahnsson 1871, which was written in Swedish.

4 Author's translation.

5 In spite of the similarity, the term lause is not borrowed from English but rather derived from the verb lausua 'to utter', which may originally be a Germanic loan. 6 Subordinate clauses are finite in Finnish, and there are few syntactic differences between main clauses and subordinate clauses.
} 
clauses, or units larger than clauses, joined with connectors other than conjunctions.

In Iso suomen kielioppi, the first comprehensive Finnish grammar based on both written and spoken corpus data (Hakulinen et al. 2004), the concept of clause relies on the finite verb, consistently with early grammars (e.g. Jahnsson 1871, Setälä 1926; see above). Finiteness in Finnish is defined through tense, mood and person marking on the verb. Nonfinite verbal elements such as participles and infinitives, even if they have their own arguments, are not considered clausal in Finnish grammar. Thus Hakulinen et al. (2004) define lause, which might be translated as 'clause', as an element whose nucleus is the finite, person-marked verb (Hakulinen et al. 2004: 827). Hakulinen et al. do acknowledge that there are degrees of clausehood (834), and that even verbless utterances can function on their own as independent utterances; such utterances are, however, considered "structurally deficient" since they lack a finite verb (839-840; but see Siro 1964).

In discussing other, central elements besides the verb which may be included in a clause, Hakulinen et al. (2004) evoke the concept of the clause core, which includes arguments of the verb: subject (also marked on the verb), object and adverbial complement(s) (Hakulinen et al. 2004: 827; see also Helasvuo 2001, where the concept 'core' is critically examined). This grammar also does away with the term virke for the description of spoken Finnish, retaining it only as an orthographic unit in written language. Reminiscent of Hakulinen \& Karlsson 1979 , the concept lause here still corresponds most closely to the concept of $\mathrm{S}$ (entence) in autonomous grammar, since it is noted that a lause can be either simple or complex (an yhdyslause 'combination clause; clause combination'). Thus the concept lause here does not really differentiate between a unit consisting of just one finite verb and its possible arguments and adjuncts (as in the first definition on p. 825) and a unit consisting of more than one such unit.

The Finnish clause, especially the clause core, does emerge rather clearly as a tightly organized structural unit (Helasvuo 2001). Arguments are case marked. The subject and the verb are especially clearly bound, since the verb shows morphological agreement with the subject and although subjects are not obligatory, in spoken Finnish they are usually present. Both of these facts, the indexing of the subject on the verb and the presence of separate subject (pronoun) arguments, make Finnish rather different from Japanese, which we will examine below. If there is an object in a Finnish clause, it is also case marked; the choice among the three object cases depends on, among other factors, the polarity of the clause, the nature of the verbal action, and the presence of a subject. Adverbial complements and adjuncts are also case marked for their syntactic or semantic role in the clause. The following example illustrates this.

(1) SG151 Kauppi

1 Susa: mutse-n takia-pa-s mie nyt täs aattel-i-n-ki et but 3SG-GEN cause-CLT-CLT 1SG now here think-PST-1 SG-CLT COMP $\mathrm{mm}$ but that's why I was thinking just now that 
jos mie sa-isi-n vaik kuukaude-ks tai kahe-ks

if 1SG get-COND-1SG even month-TRA or two-TRA

(what) if I got (work) even just for a month or two

kuukaude-ks tö-i-tä. month-TRA work-PL-PAR

months.

4 Miia: $\quad \mathrm{mm}$

PRT

$\mathrm{mm}$,

The verbs aatella 'to think' and saada 'to get', in lines 1 and 2 respectively, are both marked for first person with the morpheme - $\mathrm{n}$ (in addition to tense and mood), showing agreement with the overt first person subject mie ' $\mathrm{I}$ ' (which is in its zero-marked nominative case form - nominative case is not glossed in our examples). Likewise, the object töitä 'work' in line 3 is case marked as such with partitive case (one of the three object cases). Note also that the temporal phrase kuukaudeks tai kaheks kuukaudeks 'for a month or two months' (1.2-3) is case marked with translative case, indexing the semantic role of the NP in the clause, and that the numeral modifier kaheks is also translative, governed by its head noun. Importantly, note also that the recipient, Miia, waits to issue her response token until the object of the clause, töitä 'work', projected by the verb saisin 'would get-1SG' (line 2) is issued (line 3). In sum, Finnish clauses form rather tight syntactic packages due to the elaborate case and person marking, and since arguments are overt, and the verb comes relatively early in the clause (Finnish is $\mathrm{SV}(\mathrm{X})$ ), syntactic and actional projection is early as well; recipients are able to project the end of the turn and its social action early, and therefore are able to plan and time their response(s) appropriately (cf. Thompson \& Couper-Kuhlen 2005).

In spite of the tightness of clausal units in spoken Finnish, Finnish utterances can, of course, also take non-clausal form. Consider the example below.

(2) SG346 Koho

03 Kerttu: tää parsakaali on ihan tosi hyvä-ä= DEM1 broccoli be.3SG quite really good-PAR this broccoli is really good.

04 Sanna: =mehevä-ä juicy-PAR juicy 
05 Eeva: $\quad \mathrm{mm}-\mathrm{m}$

PRT

Yeah/ I agree. ${ }^{7}$

06 Kerttu: nii o

PTCbe.3SG

Yes (it) is.

As can be seen, a Finnish utterance or turn at talk can consist of an adjective as in line 04, or just a particle, as in line 05. We might of course consider $04 \mathrm{a}$ 'symbiotic guest' of the clause in 03 , since it relies on that prior clause for its interpretation and, being in the partitive case, is syntactically formatted to fit it (Auer 2014). On the other hand, Eeva's particle turn in line 05 is a response to Sanna's turn in line 04. It could be also said to rely for its interpretation on the prior turn. Thus it is not clear whether non-clausal utterances such as 04 and 05 are in fact fully 'independent' units. As suggested by Thompson (this volume; see also Thompson, Fox \& Couper-Kuhlen 2015), it is a property of responsive turns to rely on preceding clausal units for their interpretation, and thus non-clausal units may actually be considered to be evidence for clausal orientation by their speakers.

At the same time, both of these utterances do stand on their own. Furthermore, we may ask whether many full clauses might also be dependent for their interpretation on prior discourse. For example, line 06, consisting of the adverb/ particle nii 'so' and the finite form of the copula o 'is', is clausal in form, as it contains a finite verb. This shows that clausal utterances can also be rather minimal in Finnish, and occur without any overt arguments. This turn is responding to the turn in 04 , a non-clausal utterance, and thus relying on that turn for its interpretation. This indicates there may actually not be that big a difference between responsive turns and other kinds of turns, and, on the other hand, clausal vs. non-clausal turns in terms of reliance on prior turns (see also Linell 2009:229). In addition, response tokens can be thought to do their own social action of responding or otherwise reacting to what went before (Fox, Couper-Kuhlen \& Thompson 2015), and in that sense, they can be seen as independent units

In this section, we have seen that grammatical descriptions of Finnish have heavily relied on the concept of the clause. We have also seen that although Finnish clauses may emerge as syntactically tightly bound units, Finnish utterances can also be rather minimal, relying on contextual factors such as preceding turns for their interpretation. Next, we will turn to Japanese, which presents a somewhat different picture from Finnish.

\subsection{Japanese}

7 The particle $\mathrm{mm}$ in its various manifestations is highly resistant to translation. The translation is here provided only to show that the use here indicates agreement or affiliation. 
In this section, we will review the treatment of some structural units by major Japanese grammarians: from very early on, those grammarians were aware that 'sentences' in Japanese can be represented even just by a predicate. So we will highlight the primacy of unit types in Japanese, particularly of the predicateonly format, which are shorter than clauses in Western languages.

According to Kinsui (1997:127), there were some Japanese scholars who published high quality work on inflectional forms and parts of speech during the Edo Shognate period. After Meiji Restoration (1868), the huge wave of Westernization inspired an effort by researchers to try characterizing the Japanese language using the Western linguistic notions (See also Hida 2007, Nitta 2007), which were originally developed to account for structural characteristics of European languages and thus may not have necessarily been appropriate to capture non-Western languages properly.

Otsuki (1897) was one of the first scholars to introduce the Western notion of bun 'sentence', defining it as a "complete expression of one's thought" (Sato: dic 242; cf. Setälä 1926). He also posits the contrastive notion of ku 'clause', calling it an "incomplete" expression (251). He says that when two sentences are combined to become one sentence, the form of the predicate of the first 'sentence' changes (e.g. through affixation), which turns the first 'sentence' into a 'clause.' Furthermore, Otsuki claimed that bun in Japanese requires a shugo 'subject', i.e., a thing or event that comes to one's mind first, and a setsumeigo 'explanatory word' i.e., words which refer to the action or state of a thing or state' (251-252).

Yamada (1924), who is known for his cutting-edge and influential documentations of the Japanese language in the early 20th century, criticized Otsuki's formulation based on the fact that it can not capture one-word sentences such as kaji! 'Fire!' (see similar observation by Setälä on Finnish (1926: 13; 40); also cf. Siro 1964 and Hakulinen et. al. 2004 for Finnish). Instead, Yamada, characterized a 'sentence' as a linguistic expression of an integrated idea, and allowed sentences to include something other than the combination of a subject and a predicate (e.g., 1924:428, 1978:89). His idea of 'sentence' includes a wide range of thought-related activities such as explaining, interrogating, ordering, expressing emotions and so on (Yamada 1924: 441).

Yamada also used the term $\mathrm{ku}$, which he characterized as the basic structural unit constituting a bun 'sentence.' When ku is put in actual use, he calls it bun (1924: 425-426, also Nitta 2007 254). Yamada's ku seems to include what we may call a clause (Nitta 2007:254) ${ }^{8}$ and he developed his liguistic analyses centering around ku. For example, he proposed two types of ku clause: juttaiku '(lit.) predicating clause' and kantaiku '(lit.) vocative clause'.

8 Yamada states that clause in English mainly corresponds to a dependent type of ku (but does not cover other ku) and German Satz should be closer to the notion of ku (1924:426, cf. Nitta 2007:254). 
According to Yamada, juttaiku 'predicating clause' centers around a predicate (1924: 441). He says that juttaiku normally contains a subject and a predicate as in hana wa kurenai nari 'the flower is red' (1924:428, Nitta 2007:254), but the subject does not always appear in instances such as imperatives or in statements referring to the speaker her/ himself (1924:446-447), whereas a predicate is the most important constituent (441). Predicates, according to Yamada, include adjectives, verbs including existentials, and nouns (1924:336-445). This definition seems to be shared by Japanese researchers thereafter.

Yamada points out that kantaiku 'vocative clause' consists not of a subject and a predicate, but of a noun phrase (with final particles), e.g., taenaru fue no ne yo '(lit.) a beautiful flute sound' (1924:429). Yamada says kantaiku takes the vocative format associated with the expression of one's wishes or emotions (1924: 433), whereas juttaiku takes the format of a logical proposition $(1924: 429) \cdot{ }^{9}$

Importantly, Yamada went beyond a single clause and extensively discussed the phenomenon of multiple clause combinations within a sentence (bun), dividing them into three kinds: (1) juubun: the predicate in the first clause takes the continuative form and combined with the second (what is called the 'main') clause; (2) goobun: the two clauses are joined with a conjunctive particle; (3) yuuzokubun: a clause becomes one part, such as an argument or oblique etc., of a higher clause.

Watanabe $(1953,1974: 19,54-55)$ carefully reviews Yamada and other researchers' work and develops the analysis of bun 'sentences'. He writes that it is important for a sentence to have sozai ('(lit.) material' - roughly meaning 'content expressions') wrapped by chinjutsu 'modality' (e.g., declarative, interrogative, exclamation, and vocative). Whether sozai of a sentence consists of only one noun (e.g. hana 'Flower!') functioning as the predicate or a proposition including a predicate and a related noun (e.g. hana ga saiteiru 'A flower is blooming') is not essential for a sentencehood: Instead, Watanabe emphasizes that chinjutsu 'modality' is the key part to turn the content expressions into a complete sentence.

Following Watanabe, Teramura (1982:51) also divides a single sentence into two parts, calling them koto (equating it to Fillmore's Proposition) and muudo (equating it to Fillmore's Modality). He says koto 'proposition' consists of the stem of predicate and its argument, and continues that an argument is optional in Japanese (1982:55).

\footnotetext{
${ }^{9}$ Minami (1974: 107-108), a more recent advocate of Yamada's work, acknowledges Yamada's two types of ku, i.e.,juttaiku and kantaiku and additionally proposes a subcategory for kantaiku, called hyoodai 'titles/ labels/ signs.' It includes, for example, a name of an institution, a sign of a shop, a price tag at a supermarket and so on. He admits that normally those examples have not been treated as bun 'sentences,' but writes that they represent the reality in language and should not be ignored in linguistic research.
} 
Perhaps due to stronger influence from Western linguistics, recent years have seen shifts in research focus and associated terminological changes. So, for instance, now the term setsu is generally used as the closest translation of 'clause' in Japanese linguistics, whereas ku would be the closest equivalent of 'phrase'. Take Masuoka and Takubo (1992) for example. They call a jutsugo (which would be translated as predicate in English) "the central element of a bun 'sentence'” (1992: 2) and state that there are also elements that are relevant to the predicate in a sentence: arguments (hosokugo 'words which supplement the meaning of the predicate'), topic phrases (shudai 'theme') and modifiers (shuushokugo 'modifying words' such as adjectives and adverbs).

In discussing 'sentences,' Masuoka and Takubo distinguish tanbun 'simplex sentence' and fukubun 'complex sentence,' and note that the latter consists of smaller units setsu 'clauses,' i.e., the chunks centering around predicates. We can see that their treatment of setsu and bun is basically parallel to their western traditional (or English-based) counterparts, i.e., clause and sentence. Among the clauses in fukubun, they say the clause which involves the predicate at the sentence-final position serves as the main clause, and other clauses are called subordinate clauses (1992: 4-5).

To our interest, Masuoka and Takubo mention that there is a group of sentences which occur without any overt predicate marking (i.e., they call it mibunkabun 'unanalyzed sentences' which corresponds roughly to Yamada's kantaiku unit 'vocative clause', see Iwasaki 2014 for discussion of a relevant topic). Unlike earlier and more traditional work, their treatment of it is minimal: only two pages in the entire volume in contrast to 134 pages dedicated to predicate-based sentence (i.e., 102 pages on simplex sentence and 34 pages on complex sentence). It is in sharp contrast with how these structural units were treated by their predecessors Yamada, Watanabe and Minami, who published only or mainly in Japanese and thus were more or less independent from the Western scholarship: they described Japanese using their own structural units and labels, rather than simply adopting the structural units developed for European languages (which thus might not be appropriate for other languages).

In sum, many, especially more recent, Japanese grammarians' formulations of clauses and sentences have been predicate-based, similar to how the equivalent units in Western languages are treated. However, from very early on, Japanese grammarians were also aware of unit types in the shape of what would be described as less than clauses in Western languages, particuarly kantaiku unit (lit. vocative clause, consisting of even one noun). Hence, they can be said to represent a more 'inclusive' view of clauses and sentences in contrast to a more structurally rigid view of clauses/ sentences (i.e., predicate + argument) found in the Western tradition. In Japanese, the syntactically and/ or semantically related elements to the predicates (e.g., arguments, topic nouns) are not obligatory in order to have a complete clause and sentence. In contrast, expressions of modality are considered to be the key to make sentences complete.

In this section, we have seen that the terms $\mathrm{ku} / \mathrm{setsu} /$ bun have been used differently across researchers in different time periods. In particular, it 
illustrated that traditionally, the term ku was used by various grammarians to refer not only to clauses but also to phrasal units: however, more recent grammarians specifically use the term setsu to refer to clauses and ku to refer to phrases (Nitta 2007: 254), the distinction inherited perhaps from the study of European languages.

The following excerpt represents quite a typical pattern observed in naturally occurring everyday talk in the language. It illustrates what Japanese utterances are like in conversation, in that predicates without explicit arguments are prevalent whereas predicates with explicit arguments belong to a definite minority. It is in sharp contrast with languages like English, where subjects are compulsory as discussed in Section 1, or Finnish, where subjects are indexed on the verb, and in spoken Finnish. usually with overt subject NPs, as shown in Section 2.1. Please note that arguments are also not (co-)indexed on the predicate in Japanese:

(3) Kurieitibitii 'Creativity'

W (wife) and S (husband) are talking over dinner about work-life balance as academics.

$1 \mathrm{~W}$ : yappari atashi, $\quad$ W: $\quad$ After all, I, after.all I

2 kenkyuusha toshite researcher as

3 .. mijuku na no ne. immature COP PCL PCL

$4 \mathrm{~S}: \quad$ (0) mijuku da yo. immature COP PCL

S: $\quad$ (lit.) Are immature.// (Yes you) are immature.

$5 \quad$... soko made iu.

$6 \quad$ ((Noise of plates))

7 ... soko made iu ka.

$8 \mathrm{~W}: \quad \ldots \mathrm{n}=$

9 ... tabenaide ,

10 warui kedo. bad but there till say over.there till say PTCL

W: well,

Do not eat (what I have cooked),

(lit.) Say up to that point.// (How dare I) say such a thing (that directly).

(lit.) Say up to that point. / / (How dare I) say such a thing (that directly). eat.prohibition too bad, but. 
$11 \mathrm{~S}: \quad(0)$ hora. VOC

12
S: $\quad$ See,

(lit.) began.//

There (you/she) goes again.

In lines 1 through 3, W, who struggles to balance work and her private life, wonders if she is immature as a researcher. In line 4 , her husband Simmediately agrees with $\mathrm{W}$ by recycling the predicate mijuku 'immature' which she used and calling her 'immature'. Then in lines 5 and 7 , he jokingly produces metacomments soko made iu ka '(How dare I) say such a thing (that directly)' about his own speech act of saying such a harsh thing to his wife. It is a fixed expression of metacomment about someone who says things too frankly. In lines 8-10 the wife sounds playfully angry at her husband who insulted her: she takes the revenge by telling him that she would not allow him to eat what she has cooked. Then in line 12, S gives a metacomment about W's speech act that her usual thing (sulking in this case) has started. Hajimatta '(lit.) began' is another fixed expression referring (in a mildly negative/ teasing tone) to someone's starting a (verbal) routine.

When we view the sequence in terms of linguistic structure focusing on syntactic units, we find predicate-based utterances with no fully-specified argument(s) most frequently. One may argue that W's first utterance from lines 1 through 3 would be considered the only case of a "well-formed" clause, if we follow an English-based definition of a clause by saying that it contains an adjectival predicate (mijuku na no ne 'am immature' in line 3) and a related NP (atashi 'I' in line 1) which may be considered to be an argument or a topic of the clause..$^{10}$

The rest of the excerpts, however, includes a sequence of predicates (lines 4, 5, 7, $9,10,12)$. Notably, none of them contain explicit arguments: for example, in line 4, S repeats W's adjectival predicate mijuku da 'immature COPULA.' Lines 5 and 7 are verbal predicates without any arguments. Line 9 is an imperative, which lacks the subject argument as found cross-linguistically. Line 10 warui kedo 'too bad but.../ sorry for X-ing but' is again an adjectival predicate. The expression hajimatta 'began' in line 12 is a verb with no argument NP.

This excerpt demonstrates that speakers accomplish a wide range of social actions using less than full clauses, especially the predicate-only format (cf. Thompson and Couper-Kuhlen 2005): Line 4 is an aligning response by S who repeats the adjectival predicate mijuku da ${ }^{11}$ meaning be immature' uttered by $\mathrm{W}$ in line 3 who assessed her own academic performance negatively. S makes metacomments in lines 5 and 7, which lead to W's directive of prohibition and a mitigation in lines 9 and 10. W's direct prohibition invites $\mathrm{S}$ to produce another metacomment in 12. It also shows that fixed expression s of the predicate-only

${ }^{10}$ Japanese copula da is used with nouns and nominal adjectives and exhibits inflection.

${ }_{11}$ The forms na and da found in line 3 and 4 respectively are two variants of the copula. 
format appear multiple times and play key roles in local interactional management. ${ }^{12}$

In sum, the data from Japanese everyday talk, as well as Japanese scholars' analyses over the years, suggest that less than full clauses, even predicates (i.e., verbs, nouns, and adjectives) without any related NPs, are more of a primary option in Japanese (Laury and Ono 2014), rather than standard clauses with overt NPs. This itself might be familiar to those who work with Japanese conversation. However, we also find it worth introducing similar observations made in the work of Japanese scholars spanning more than a century which is mostly available only in Japanese. The primacy of predicate-only utterances in Japanese is structurally in sharp contrast to English, and also to Finnish to some degree. We will now turn to a discussion of our qualitative and quantitative findings regarding the use of clauses and predicate-only utterances in Finnish and Japanese everyday conversation.

\section{Clauses and predicates as units in interaction}

In early conversation analytic work, it was assumed that clauses are the building blocks of turns and TCUs, together with sentences, phrases, and one-word constructions; these were thought to have points of possible unit completion and therefore allow projection, crucial for the organization of turn taking (Sacks et al. 1974: 702, 721). It has been noted that the edges of such constructions are where turn transitions occur, where participants behave as though a turn has come to a completion. In later work, turn transition has been used as crucial evidence for structural unithood by interactional linguists who focus on the connection between interaction and linguistic form (e.g. Ford \& Thompson 1996; see also Ford et al. 2013: 49).

Clauses, like other linguistic units, are seen in interactional linguistics as emergent in interaction (Goodwin 1981, Ford, Fox \& Thompson 2002, Helasvuo 2001, Couper-Kuhlen \& Ono 2007, Linell 2013). This means that clauses, like utterances with other kinds of structures, take shape in response to many factors, including the activities of recipients (Goodwin 1979). A good example is the minimal responsive clause in line 06 of example (2) above; its format has everything to do with its being responsive to a prior turn (Hakulinen \& Sorjonen 2009). Another manifestation of the collaborative emergence of clauses is that they may also be co-constructed, built in cooperation with other speakers (e.g. Lerner 1991; Ono \& Thompson 1995; Hayashi 1999, 2003; Helasvuo 2001.).

In earlier work, it has been argued that participants orient to clausal structures in building their turns at talk, and even that clauses are 'the locus' of interaction, that is, central to the accomplishment of interactional tasks (Thompson and Couper-Kuhlen 2005; Helasvuo 2001; see also Thompson, this volume). Thompson and Couper-Kuhlen (2005) even go so far as to propose that this is so for all languages, using Japanese and English as examples, making their study

12 The pervasiveness of utterances based on formulaic language in Japanese everyday talk and its theoretical implications are highlighted in Ono and Suzuki (2018). 
highly relevant for ours. Using turn transition, joint utterance completion and incrementation as evidence, they argue that speakers of both English and Japanese use their experience with clausal formats in their own languages for projecting when utterance is likely to come to an end, and to project what social action the clause is being used to implement, but that the ways they implement this knowledge has to do with the variability in clausal formats in the two languages. ${ }^{13}$

In fact, much recent research in interactional linguistics suggests that grammatical formats are oriented to by participants. For example, Auer suggests in a recent paper that "speakers demonstrably perform (or show to have performed) a syntactic analysis of the previous utterance (2014: 534)". This would suggest that participants orient to the grammatical shape of a prior utterance and fit their subsequent contributions to it (see Du Bois 2014). Likewise, the claim that different grammatical formats are closely linked to the actions performed (Couper-Kuhlen 2014; Thompson this volume) would imply that, on some level, grammatical formats are oriented to by participants in conversation, just as it is claimed by Ford et al. that participants orient to bodily conduct as they build their actions (2013: 26).

In what follows, we bring up the evidence that has been put forward with respect to participant orientation in prior work, and also point out some of the problems we have with that notion. We will discuss the usefulness of the concept 'clause' for the analysis of Finnish and Japanese, and we will also discuss evidence for and against participant orientation to clauses from both the speaker's and the recipients' perspective. We will examine the usefulness of turn transition, joint utterance completion and incrementation as evidence for clausal orientation, ${ }^{14}$ and we will also examine whether the linguistic formatting of social actions manifest signs of speaker orientation to clausal units.

\subsection{The clause as a unit in Finnish conversation}

Quantitative facts may, in our view, be taken as evidence of orientation to a particular grammatical format. Namely, if speakers of a particular language use a certain construction very often, they could be said to be orienting to that construction on some level, since they operate with it habitually and format their utterances as such. As argued by Thompson \& Couper-Kuhlen (2005), speakers need routinized ways of implementing actions, and the most frequent patterns are certainly likely to be most routinized (Du Bois 1987; Bybee 2010).

In Finnish conversational data, most turns at talk are clausal, given the definition of the clause in the Finnish grammatical tradition as described above, that is, units consisting of a finite verb and possible arguments. However, overt

13 Likewise, it has been argued that grammatical choices are meaningful for action construction (e.g. Couper-Kuhlen 2014; Kärkkäinen \& Keisanen 2012; Fox 2007). 14 An anonymous reviewer suggests that turn projection is another area which might be useful to examine, which we we hope to do in future studies. 
arguments are not criterial for clausehood in the Finnish grammatical tradition though subject person is always present as it is marked on the finite verb.

Our analysis of more than 750 turns at talk from both dialogic and multiperson Finnish conversations showed that approximately $60 \%$ of turns were clausal (consisting of one or more clauses.) The second largest group was made up of turns consisting of one or more particles (approximately 20\%). Turns that could not be syntactically analyzed (laughter, other sound objects) accounted for approximately $7 \%$ of the turns. The fourth largest category were turns consisting of NPs (approximately 5\%). No other structural formats came even close to these..$^{15}$ These facts show, on the one hand, that while $40 \%$ of turns at talk are non-clausal, Finnish speakers do routinely format their utterances as clauses, and that clausal utterances are much more common than any other type.

These results are consistent with those arrived at by Ikola et al. (1989). In their interview data, 'sentences' (by which they mean, roughly, utterances) which consisted of only one clause were the most common type (1989:7). Ikola et al. also note (1989:35) that the most common type of one-word utterance was one consisting of only the finite predicate (43.8\%), showing that even minimal utterances strongly tend to be clausal; the next most common one-word utterance type were 'response adverbials', that is, response particles (33.3\%) and other adverbials (7.5\%) or conjunctions (5.1\%). Other types of forms all accounted for less than $2 \%$ each.

These quantitative facts could be taken as evidence for a claim that Finnish speakers actually, at least on some level, orient to clauses, since they routinely format their utterances as clauses. However, it is also possible to use qualitative facts as evidence for orientation (or lack thereof) to clauses.

One piece of evidence for clausal orientation by speakers are increments, turn extensions which are shaped to fit syntactically with a clause which has already been brought to a syntactic, prosodic and pragmatic completion (cf. Thompson \& Couper-Kuhlen 2005; on incrementation, see Ono \& Couper-Kuhlen 2007). Speakers of Finnish can be observed to provide syntactically fitted extensions to their clausal turns, resulting in well-formed clauses, and speakers could thereby be thought to be orienting to clausal structures. Consider the following example, taken from a conversation between two women friends on New Year's Eve. It is common for Finnish families to keep Christmas decorations up until well after Christmas, at least until Epiphany, January $6^{\text {th }}$. In the excerpt below, Tarja compliments Kati on her Christmas tree.

(4) SG398 Kuohuviini

1. Tarja: $>(00)$ tte $<$ jaksanu hankkia hienon be-2PL have.energy-PPLE get-INF fine-GEN

You have (even) managed/ had the energy to get a beautiful

15 We thank Karita Suomalainen for her careful analysis of the syntactic makeup of turns in Finnish conversation. 
4. Kati: se on «pakk:ho>. 3SG be.3SG unavoidability it's a must.

6.

\author{
joka joulu (.) ( $\left({ }^{\circ}\right.$ tehäs se $\left.{ }^{\circ}\right)$. \\ every christmas do.INF 3SG \\ to do it every Christmas.
}

Although Kati builds her turn in line 4, se on pakko 'it's a must', as a complete clause syntactically and prosodically, at line 6 , after her addressee does not respond in spite of the 0.4 second pause, she adds an increment (Ono \& CouperKuhlen 2007) which is syntactically fitted to the clause in line 4 . The increment consists of an adverbial modifier, joka joulu 'every Christmas', and an infinitival complement, tehä 'to do' fitted to the modal expression on pakko 'is a must; have to'. The form of the infinitive is the so-called A-infinitive, or 1st infinitive, the only possible infinitival form functioning as a complement of on pakko(Finnish has several infinitives). In addition, the nominative form of se 'it', the object of tehä, also fits its syntactic position - objects in Finnish can be either accusative, partitive or nominative, ${ }^{16}$ depending on a number of syntactic, semantic and pragmatic factors. This could be considered orientation to a clause; she builds her two consecutive utterances in such a way that they together form a syntactically well-formed clause.

This example also shows the formatting of social actions as clauses. Tarja's turn in lines 1-2 is a compliment, and it is formatted as a clause (the finite verb form is olette 'be-2PL', in the verb complex olette jaksanu). And Kati's turn in lines 4 and 6 is a receipt of that compliment, and it is also clausal (on Finnish compliments and their receipts, see Etelämäki, Haakana \& Halonen 2013).

So far, we have shown that speakers in our Finnish data format the majority of their utterances as clauses, and that increments to their already clausal turns are syntactically fitted to the prior clause so that they together form a clause. And we have seen that Finnish compliments can be done and receipted with clauses.

In our Finnish data, we also find counterevidence for speaker orientation to clauses. One type of counterevidence against speaker orientation to clauses are,

\footnotetext{
16 Finnish could in fact be said to have four object cases, nominative, partitive, accusative and genitive. Personal pronouns have accusative forms distinct from the genitive, but for other nominals, the accusative case is syncretic with the genitive case, due to historical changes. Therefore, some grammars will say that objects in Finnish can also be genitive.
} 
obviously, utterances that are not clausal; we have seen examples of these in (2) above. However, as discussed above, non-clausal utterances such as mehevä-ä juicy-PAR' could be considered to be analeptic to the just prior clausal utterance, so that they would 'borrow' the structure of that prior utterance as 'symbiotic guests' (Auer 2014), and to be interpretable on that basis. On the other hand, as also noted above, all utterances presumably are interpretable in context, and the need to argue for structural borrowing may result from a conscious or unconscious reliance on a model of grammar in which full clauses are the unmarked case.

Besides the way that speakers format their utterances, other participants can also be shown to orient to clauses. A prime example of clausal orientation is next-turn onset at clause boundaries. Finnish speakers regularly start their subsequent turn precisely at the point where the prior speaker has come to the end of a clause ${ }^{17}$. Our example (1) above can be counted as evidence for this, as already suggested. Consider also example (5) below, taken from a conversation where several music experts are identifying musicians in a collection of photographs.

(5) SG435 Valokuvat_Maaler

05 Jouni: ${ }^{\circ} \mathrm{mm}^{\circ}$ toi on se onks toi se Maaler-kuva. DEM2 be.3SG DEM3 be.3SG-Q-CLT DEM2 DEM3 [2NAME]-picture um that is the is that the Mahler picture

06 Matti: $\mathbf{o}^{18}$,

be.3SG

yes it is

07 Päivi: $\underline{\text { onn. }}$

be.3SG

yes it is

Jouni's turn involves a change of plan: he starts his utterance as a statement, but after the initial toi on se 'that is the' he restarts with the copula with a interrogative clitic, on-ks and reverses the word order so that the subject toi 'that' is now postverbal, turning his utterance into a question. This turn does not constitute a single clause, but rather part of one clause (toi on se 'that is that/ the' which here, prosodically and pragmatically, is not a complete clause) immediately followed by another, complete clause (onks toi se Maaler-kuva 'is that the Mahler picture'). However, it seems reasonable to us to suggest that the ease and fluency with which the turn is formatted may be counted as orientation to the clause as a unit. That is, although the turn contains a significant self repair,

17 Vatanen (2014) shows that, conversely, turn onset before the prior turn has come to its projected end is exploited by speakers of Finnish for particular ends. This could be taken as a sign of awareness of a clausal boundary as an unmarked position for nextturn onset.

18 The form 0 is a short variant of the third person singular present tense copula, pronounced as on in lines 05 and 07. 
the turn is delivered without any pauses or hearable signs of hesitation. The speaker goes seamlessly from the initial affirmative copula clause start to the interrogative clause. We take this as evidence that in this turn, involving the change of plan from a statement to a question, he orients to clausal formats.

The responses by Matti (line 06) and Päivi (line 07) also come at clausal boundaries. Note that Matti's response comes immediately after Jouni's turn ends, and he has no problem timing his turn exactly at the closure of Jouni's turn, at the point where a full clause ends, although Jouni's turn involves a change of plan and is as such complex. Päivi's response follows immediately after Matti brings his minimal clausal response into completion.

The responses in lines 06 and 07 are of the type that has been called verb repeat responses in Finnish linguistics (Hakulinen \& Sorjonen 2009). This response involves a repetition of the finite verb from the prior utterance; it expresses agreement with that prior turn. Verb repeat turns are a very common type of response in Finnish. A recent study (Laury 2018) showed that approximately $30 \%$ of Finnish responses to questions, assessments and informings are verb repeats; the other common response type is the particle response, which accounts for another $30 \%$ of responses. No other syntactic constructions are as common as responses as these two types.

A verb repeat can be considered orientation to the clause as a unit, since it involves repetition of the key element of the prior clausally formatted turn. That is, the repetition of the finite verb can arguably be thought to involve syntactic analysis of a prior clausal turn ${ }^{19}$. Also, by themselves, verb repeats are by definition clauses since they consist of a finite verb, as in lines 06 and 07 , which repeat the finite verb on in Jouni's turn in line 05 (where the verb appears in both affirmative and interrogative form; but the responses most likely orient to the full clause, which is a question). Thus verb repeat responses can be said to show orientation to clauses merely by their clausal formatting.

The formatting of repair can also manifest orientation to the clause. Consider the next example, which comes from the same conversation as example (5). At this point in the conversation, Päivi has been looking at a particular photograph for a while. She then turns toward Matti, holds up the photograph, and addresses Matti.

(6) SG435 Valokuvat_kummitäti
101 Päivi:
[个tää ol-i
sun kummi\#täti\#]
DEM1 be-PST-3SG 2SG-GEN godmother

\footnotetext{
19 There is also no doubt that formulation of a response involves semantic and pragmatic analysis as well, since participants must understand the meaning and pragmatic import of an utterance in order to respond appropriately to it. Arguably, a verb response requires more syntactic analysis than, say, a particle response, since it involves a repetition of a certain component of the prior turn. Verb repeats are usually done in the same tense, person and mood as in the prior utterance, although they may also manifest deictic shifts. They may be done in the same or different polarity.
} 
this was your godmother

\begin{tabular}{|c|c|}
\hline 102 Jussi: & $\begin{array}{l}\text { [(kovin)] } \\
\text { very } \\
\text { very }\end{array}$ \\
\hline 103 Liisa: & $\begin{array}{l}\text { [joo. ] } \\
\text { PRT } \\
\text { ves }\end{array}$ \\
\hline
\end{tabular}

104 Päivi: [nịi-hän ] se oli. ((Matilta))

PRT-CLI DEM3 be-PST-3SG ((to Matti))

that's how it was, right.

105 Matti: $\begin{aligned} & >\mathbf{e i}-\mathbf{k u}<\quad \text { Jukka-n. } \\ & \text { NEG.3SG-CLI [1 nameM]-GEN } \\ & \text { no,Jukka's }\end{aligned}$

106

Päivi tells Matti (line 101) that the person in the photograph she is showing to Matti is his godmother, and then in line 104, suggests that this is the case, using the clitic-hAn, which expresses that the information is shared knowledge (Hakulinen et al. 2004: 797). Matti responds in line 105 using the repair particle eiku (Sorjonen \& Laakso 2005, 2010) and providing the form Jukan, 'Jukka-GEN', a repair of the element sun 2 SG-GEN (line 101). This item can be interpreted as the repair of just that element in Päivi's turn in line 101 due to the match of the case element. In that sense, Matti, in choosing the form of the repairing element, might be said to be orienting to the argument structure of the clause in Päivi's turn, on which it could be said to be analeptic (Auer 2014). We could, of course, also argue that Matti's turn is in fact only orienting to the form of the NP in which sun 'your' is a modifier of the noun kummitäti 'godmother'. However, the repair only makes sense in the context of this particular sequence, and as response to the proposition Päivi's turn in line 101 represents; crucially, Matti is not only repairing the NP sun kummitäti 'your godmother', but rather disagreeing with or repairing the claim that the person in the picture, represented by tää 'this', is his godmother. Surely what the participants are concerned with here is establishing reference and constructing intersubjective understanding rather than constructing a syntactic unit. However, morphosyntax, here, a case matching the case of an earlier repairable, is a tool which is put to use toward this end. The case of the NP can, in this context, only be understood analeptically, within the framework of the earlier clause.

Another conversational phenomenon which has been considered to manifest orientation to the clause as a unit is joint utterance construction (Thompson and Couper-Kuhlen 2005; Hayashi 2003). Joint utterance construction is a practice in which a speaker completes a structure, such as a clause, which has been started by another speaker. Participants in Finnish conversation can also be shown to orient to clausal organization when they complete, or co-construct a clause 
started by another speaker, as shown in the next example, which comes from a holiday gathering of members of an extended family (for further examples and discussion, see Helasvuo 2001: 42).

(7) Joulukahvit

10 Liisa: >kyllä<tää jo?

PRT DEM1 already

This one already

11 oli l- leikkitarhassa sanonu, be-PST.3SG daycare-INE say-P.PPLE had said at daycare,

13 Sini: $\mathrm{mm}:$ ?

15 Keijo: sukupuolen määritelmän, gender-GEN definition-ACC the definition of gender

In this example, the grandparents of a small child present at the gathering, Liisa and Keijo, initiate the telling of an anecdote meant to illustrate the precociousness of their grandchild. Liisa starts the anecdote (1.10-11), and receives a noncommittal continuer, $\mathrm{mm}:$ :, from another participant (l.13). At this point, Liisa's contribution is incomplete both syntactically and prosodically as well as semantically, since it lacks an expression of what the child had said, the object of sanonu 'said' but after a minipause, Keijo (l.15) provides a characterization of what the child had said, using an accusative NP syntactically fitted to complete the clausal unit begun by Liisa. By doing so, Keijo can be seen to be orienting to the clause as a unit.

We have suggested here that in our data, participants in Finnish conversations can be shown to orient to clauses because they regularly format their utterances as clauses, build increments which are syntactically fitted to already completed clauses, and initiate their turns at the completion of another speaker's clausal turn. Clausal turns can also be co-constructed. However, we also find counterevidence to orientation to clauses: speakers of Finnish also use nonclausal turns.

Thompson (this volume) suggests that formatting of social actions as clauses shows that the clause is a relevant unit for participants in English conversation. Our Finnish data indicate that assessments (example 2), compliments and their receipts (example 4), questions (example 5), and even one-word responses (examples 2 and 5 ) are formatted as clauses. This may also be taken as evidence 
of the robustness of the clause as a format in Finnish conversation, and perhaps as evidence of speaker orientation to clauses, however given the caveats we have discussed above.

Next, having suggested that clauses are indeed relevant for the organization of Finnish interaction and that speakers of Finnish can be thought to orient to clausal formats both quantitatively and qualitatively, we will examine Japanese conversational data in order to see whether clausal formats are also useful for the analysis of Japanese interaction and oriented to by Japanese speakers.

\subsection{The predicate as a unit in Japanese conversation}

As discussed in section 2, predicates, along with the occasional use of related NPs, are considered to be the key by Japanese traditional grammarians in their discussion of bun, or more recently of setsu. Even though setsu is now the standard translation of the term 'clause' in English, note that what is actually represented by Japanese setsu is quite different from a typical 'clause' discussed in standard references in linguistics (see Section 1), where both the predicate and its argument(s) appear overtly.

In this section, we hope to show that full clauses (i.e., utterances consisting of a predicate and its arguments) are rather rare in Japanese conversation, and also that it is difficult to establish participant orientation to such units. As we did for Finnish, we will do this first by examining quantitative figures concerning clausehood and then by closely examining linguistic and interactional behaviors which have been used to establish participant orientation to the clause: joint utterance construction, incrementation, and social actions (Thompson and Couper-Kuhlen 2005).

It should be noted that the rarity of full clauses in general and the abundance of predicate-only utterances in particular in Japanese conversation are clearly related to the well-known phenomenon of 'zero anaphora' where what would be considered arguments of predicates in Western languages like German and English are not overtly expressed in equivalent Japanese utterances, especially in spoken language (Clancy 1980, Hinds 1980, 1982, Martin 1975, Maynard 1989, Okamoto 1988, Ono and Thompson 1997, and Ono, Thompson and Suzuki 2000). This is a pervasive phenomenon resulting in the abundance of types of utterances illustrated in (3) above. Given that arguments are not (co-)indexed on the predicate in Japanese, the rarity of full clauses and the abundance of predicate-only utterances might be unexpected especially to those who have not examined Japanese conversation, though it is clearly demonstrated by quantitative figures.

So, for instance, Shimojo (2005:69) reports that in his conversational data, $68 \%$ (2758/4049) of subjects and 49\% (511/1038) of direct objects are not 
expressed overtly, showing that predicate-based utterances which are not full clauses are the norm in conversational Japanese. ${ }^{20}$

In addition, Matsumoto (2003:128) shows that out of 1121 instances of what she considers 'clause' in her conversational data, 44\% (492/1121) are without overt core arguments (i.e., none of A, S, or O appeared) ${ }^{21}$ Further, among these 1121 clauses, 764 are intransitive, 22 and 58\% (444/ 764) of them are found without the subject. The remaining 357 clauses are transitive, ${ }^{23}$ and $91 \%$ (325/357) of them appear with only one or none of A or O; only 9\% (32/357) occur with both A and $0,{ }^{24}$ which again shows the rarity of what is considered a "full clause." It is clear from these figures that less than full clauses, or even predicates without any overt arguments, are what Japanese speakers orient to in the sense that that is what they produce most.

Having thus established that the type of utterance that Japanese speakers orient to most is not shaped very much like clauses in languages like English and Finnish, let us now examine Japanese conversation more closely and see whether speakers actually orient to clausal structures in building their turns at talk, and even whether clauses are 'the locus' of interaction, that is, central to the accomplishment of interactional tasks (Thompson and Couper-Kuhlen 2005; Helasvuo 2001; see also Thompson, this volume). The first instance to consider speakers' orientation to clauses has to do with joint utterance completion (aka co-construction). The example originally comes from Hayashi's work (1999, 2003) in which $\mathrm{H}$ and Kare talking about the location of the public phone in order to find each other when they meet:

(8) (in Thompson \& Couper-Kuhlen 2005:494, from Hayashi 1999: 479)

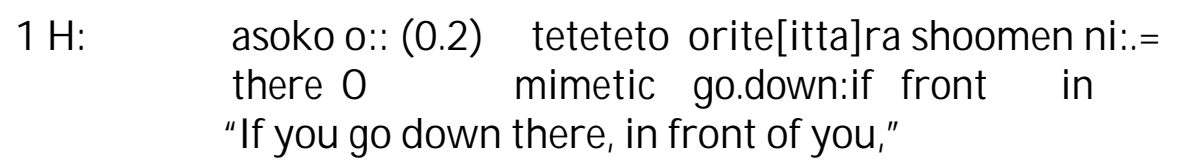

$2 \mathrm{~K}:$

[u:n]

"Uh huh."

$3 \quad=\mathrm{u}: \mathrm{n}$.

"Uh huh."

$4 \mathrm{H}: \quad$ denwa ga- ano mi[dori] no denwa ga:[:]

phone SB uhm green LK phone SB

\footnotetext{
${ }^{20}$ An anonyomous reviewer pointed out that even syntactic relations such as subject and direct object are questionble in Japanese. For relevant discussion, see Hoye 2008 and Ono and Thompson 1997.

${ }^{21}$ For clausehood, Matsumoto follows the recent tradition influenced by the study of European languages discussed earlier: She determines predicates and their arguments based on imagined fully specified clauses which are rather like English.

22 This includes figures from instransitive, adjectival, and nominal predicates by Matsumoto (2003:128).

23 This includes figures for both transitive high and low by Matsumoto (2003:128).

24 Specifically, $91 \%$ consists of $13.4 \%$ without either A or $0,4.5 \%$ only with A, and $73.1 \%$ only with $\mathrm{O}(48,16$, and 261 respectively out of 357$)$.
} 
"Phones, uhm, green phones"

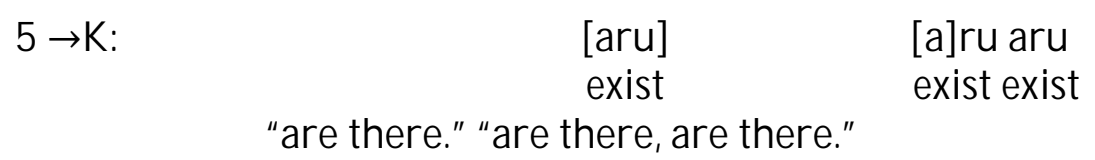

In line 1 , $\mathrm{H}$ first says 'if you go down there' in a conditional adverbial. When $\mathrm{K}$ hears H's production of the verb orite 'go down,' she delivers the response token $\mathrm{u}: \mathrm{n}$ in overlap in line 2. In line 4, $\mathrm{H}$ further specifies the location by supplying information about what would become visible to K in front after going down the stairs: green (public) phones. Overlapping with H's introduction of the green phones, K supplies what looks to be the predicate, an existential verb aru, in line 5 .

Hayashi $(1999,2003)$ and Thompson and Couper-Kuhlen (2005:494) interpret the above as a case of joint utterance completion, and point out that it is a powerful support for participants' orientation to clausal format and note that frequently, Japanese speakers co-produce only the predicate, i.e., the terminal element of the clausal format. One may argue for K's clausal orientation based on this seemingly orderly addition of the predicate. Observe the following schematization illustrating this analysis:

(9) schematization of the 'clause' consisting of lines 1, 4, and 5

\title{
[conditional adverbial]
}

H: asoko 0 .... oritettara 'if you go down there'

\author{
[locative NP] ['subject' NP] \\ shoomen ni denwa ga \\ 'in front, phones'
}

\section{[existential verb]}

$\mathrm{K}$ : aru

'are there.'

As the above shows, in H's turn, we see the sequence of a conditional adverbial 'if you go down there' and a locative NP (marked with ni) 'in front' followed by the 'subject' NP (marked with ga) 'phones': those materials, combined together, have been suggested to work as resources to inform $\mathrm{K}$ of the likely format which $\mathrm{H}$ subscribes to in the process of production: the yet-to-be-delivered element is likely a predicate and has to do with existence or visibility. So K "anticipatorily completes" (Hayashi 1999: 45) H's utterance with an appropriate choice of "the terminal element of an emerging mono-clausal unit" (Thompson and CouperKuhlen 2005: 494), which would have been possible with the knowledge of the clause coming from each speaker's experience with it.

Although the above analysis may sound reasonable at first, we would like to point out that in trying to understand the nature of aru in line 5 , we also need to take into consideration the social action relevant in the context: whether speaker 
Kis oriented to the unit clause is actually difficult to establish. Notice that there are in fact several instances of aru in line 5 produced by $\mathrm{K}$. We feel that interactionally K's aru and aruaru in line 5 are better analyzed as response tokens displaying understanding or acknowledgement towards H's description of where the phones are in lines 1 and 4, rather than as a verb which merely completes H's ongoing clause (which Thompson and Couper-Kuhlen (2005) use as evidence to say that Korients to the clause started by $\mathrm{H}$ and completed by $\mathrm{K}$ herself). ${ }^{25}$ We suggest this analysis particularly because it is reasonable to assume that interactants' primary concern is to establish a mutual understanding through negotiating a referent, not to construct a syntactic unit such as clause. And there are, in fact, a few pieces of structural and interactional evidence which support our analysis.

For one, in such a context, we also very likely find speakers using affirmative response tokens such as hai 'yeah' instead of aru, which lends support to our analysis that aru in line 5 displays an understanding or acknowledgement. Moreover, the timing of K's first production of aru in line 5 also supports the response-token analysis: namely, K produces aru in overlap with H's production of midori 'green,' rather than coming in at a more appropriate place, i.e., the end of the noun phrase denwa ga 'phones'. That is, if K's concern was to produce a clause ('joint utterance completion'), she would have produced aru at a point where it would syntactically continue H's utterance which would result in a clause, but she does not do so. So the timing of production of the first aru in line 5 makes us wonder if we are justified to say that $\mathrm{K}$ is oriented to a clause.

Furthermore, the repeats of aru cannot be easily syntactically fitted with the utterances in lines 1 and 4: multiple instances of the candidate predicate aru would not result in a well-formed or coherent clausal format. So it seems difficult to maintain that K produced the utterance in line 5 to construct a syntactic unit 'clause'. Given that response tokens tend to be repeated (e.g., Maynard 1990:410), it is in fact much more reasonable to suggest that K is simply accepting the referent 'phones' brought up in the talk by using aru as a response token (see also Ono and Suzuki 2018). In sum, aru obviously serves as the predicate of a clause in some situations, but in this particular excerpt, we find it structurally and interactionally better characterized as a response token, questioning the clausal analysis given to the utterances in line 1, 4 and 5, thus leaving the clausal orientation itself in doubt.

Another problematic yet typical example which might be used to claim speakers' orientation to the clausal format comes from an excerpt of conversation between two people, $\mathrm{R}$ and $\mathrm{H}$, talking about their mutual friend:

(10) Ryokoo 6 (adopted from Couper-Kuhlen \& Ono 2007, also used in Thompson \& Couper-Kuhlen 2005)

$1 \mathrm{R}:$... so.

25 Suzuki 2016 and Ono and Suzuki (2018) in fact propose that frequent verbs of general meaning such as existential verbs aru and iru grammaticize into response tokens. 
2 :.. hoshitara, then

3 : oon- asuko ikanakatta $\mathrm{n}$ datte. there go:not:PAST NZR hearsay

'So I hear (she) didn't go there then'

$4 \mathrm{H}$ : [doko e]?

where to

'to where?'

5 R: [oosutora]ria.

Australia

'Australia'

6 :.. akichan.

'Aki'

In lines 1-3, R first says so hoshitara oon- asuko ikanakatta $\mathrm{n}$ datte 'So (I) hear (she) didn't go there then' without specifying the agent nor the location of going. The utterance includes oon- which might be the beginning of the word oosutoraria 'Australia' which R later produces in line 5, but here in line 3 she appears to halt in the middle of the word and continues with the distal demonstrative asuko. ${ }^{26}$ Spatially, it indexes the location far from both the speaker and the hearer', but this demonstrative is also known to be used when the speaker treats the referent as information that both the speaker and the hearer know (Masuoka and Takubo 1992:38; Kuno 1973). So asuko reflects R's treating $\mathrm{H}$ as a knower of 'where (she) didn't go.' Then perhaps sensing trouble, R extends her turn in line 5 by specifying the location, oosutoraria 'Australia' in overlap with H's repair-initiating question doko e 'to where?' in line 4 (Thompson and Couper-Kuhlen 2005: 496-7). In line 6, R further specifies the actor using the noun akichan 'Aki'.

These additions look similar to the increments in Finnish that we saw above in that the addition of further material after the complete clause results in an expanded clause, and one might be tempted to use them as evidence to say that Japanese speakers are oriented to clausal structures. That, however, is clearly not attainable because Japanese canonically places the predicate at the end of the clause, and here the additions don't result in what would be considered a syntactically well-formed unit:

?so hoshitara oon- asuko ikanakatta $\mathrm{n}$ datte oosutoraria akichan ${ }^{27}$

${ }^{26}$ Asuko is a colloquial form of the dictionary form asoko.

27 Utterances such as this are actually common in spoken Japanese, which questions the predicate finality as a canonical feature of the language (Ono and Suzuki 1992). Looking 
so then there go:not:PAST NZR hearsay Australia Aki

'So I hear (she) didn't go there then Australia Aki'.

That is, generally the structure of Japanese clause doesn't allow the added materials to create an expanded syntactic unit, and thus they cannot really be used as evidence for clausal orientation.

Please note that we are obviously not denying the semantic/ pragmatic connection which the added materials oosutoraria 'Australia' and akichan 'Aki' have with the predicate ikanakatta 'didn't go' without which they could not have been produced for the first place. That is, as soon as R says asuko ikanakatta $n$ datte 'I hear (she) didn't go there' in line 3, its meaning becomes available to $\mathrm{H}$ as evidenced in his immediate question doko e 'to where?' in line 4; the connection of the actor and the location to the action of going is afforded by the semantics/ pragmatics of 'someone didn't go somewhere' just established by the previous utterance in line 3.

In other words, in this example we find the speakers trying to achieve a shared understanding by producing and processing these short utterances one at a time. This appears to be a better account of what is interactionally happening in the segment rather than saying that they are in the business of constructing a syntactic unit clause. ${ }^{28}$

So far, we have looked at examples which contain less than what is considered a full clause or even just a predicate without arguments. We have pointed out that clauses, typically discussed using English examples, are rare in conversational Japanese. Instead, these shorter utterances constitute the most common unit type which speakers orient to by producing and monitoring them bit by bit as the interaction unfolds.

The key role played by predicate-only utterances, along with occasional accompanying elements, in Japanese interaction can also be observed in the following example, which comes from a later part of the same conversation as (10). Both $\mathrm{H}$ and R are talking about their mutual friend Aki. We find a long sequence of utterances featuring predicates which are syntactically not at all like clauses found in standard references:

(12) Ryokoo

$1 \mathrm{H}$ : ... de kekkyoku paa?

into this further potentially establishing a canonical structure of spoken Japanese, however, is a topic for another project.

${ }^{28}$ A reviewer wondered if it is possible to say alternatively that the conceptual unit of clauses guides the interactants to perform the way they did. We think it is certainly possible that interactants are achieving a conceptually coherent or unified understanding as making sense is part of what people engage in, but it needs to be stressed that that is not the same with the production of syntactic unit 'clause' which we are arguing against in this paper. 
so after.all null

So (the trip) got nullified/ canceled after all? 
2 R: . ... un=daka ikanakatta $=$ toka yutte.

yes so go:NOT:PST QUO say

Yeah. (She) says 'so (I/ we) did not go'.

$3 \mathrm{H}: \quad$... okotteta?

angry:STATIVE:PST

Was (she) angry?

4 R: ... un = mo atamakichau toka itte.

yeah EMPH agnry:PERFECTIVE QUO say

Yeah, (she) goes "Darn, (I) get so furious."

5 H: ..@@@

$6 \mathrm{R}: \quad$... nanka,

well

Well

7

.. atashi yori shigoto o totta the koto da yone $=$. I than work ACC choose:PST QUO meaning COP PTCL

'(It) means (he) chose (his) work rather than me'

$8 \quad$ toka itte.

QUO say.

(she) says

As shown by the number of parentheses used in the English translation, we can see that there is a clear tendency of the Japanese predicates appearing without overt arguments. In particular, what might be considered the subject arguments are not expressed at all in this excerpt. Interestingly, however, the interactants do not seem to have difficulty understanding each other, suggesting that these short utterances are complete in their own right although they might look incomplete to those used to seeing clauses of the type found in English.

It should be noted that this excerpt represents an ordinary exchange routinely observed in Japanese conversation where individual utterances seem rather unexceptional. Moreover, the short utterances in the excerpt all perform independent actions: $\mathrm{H}$ checking his understanding of the situation with the other participant in line 1 , $\mathrm{R}$ confirming it in the form of reported speech in line 2 , $\mathrm{H}$ posing another question in line 3 , R giving a positive response in the form of reported speech in line 4 , $\mathrm{H}$ reacting with laughter in line 5 , and $\mathrm{R}$ providing a further positive response in the form of reported speech in lines 6-8. In other words, these utterances, much shorter than the syntactic unit clause found in standard references, are produced and responded to one at a time, which demonstrates further that they are in fact oriented to by the speakers themselves.

This section has shown that in Japanese conversation, predicates along with occasional overt NPs, not what is traditionally understood as full clauses, 
constitute the most common unit type which speakers orient to by producing and monitoring them bit by bit as the interaction unfolds. We have seen that these predicates serve as a vehicle to carry out a wide range of social actions, and both quantitatively and qualitatively available data has demonstrated that the unit clause is not as well oriented to in Japanese as in English and Finnish. We have also seen that some of the criteria used to identify participant orientation to clause have not been properly employed or simply do not work for Japanese.

\section{Summary and conclusions}

In this article, we have focused on the structural unit 'clause' in grammatical descriptions of Finnish and Japanese and everyday conversational data in these languages. Our overall goal was to determine if 'clause', a unit type originally established based on languages like English and other European languages, is real to speakers of these two languages, which are genetically and typologically distinct from English and each other.

Both grammatical descriptions and everyday talk have shown us that establishing 'clause' is not as straightforward as it has been assumed. In particular, we have learned that languages differ very much in how they format what might be termed 'predications'. That is, 'clause', though typically treated as a universal type of unit, does not easily fit data from all languages. It seems clear that it is a better fit for Finnish and English (for the latter, see Thompson, this volume). We have seen that many utterances, though not all, in Finnish conversation are clausal. In fact, participants can be shown to orient to clauses, although there is some counterevidence as well. Thus, even in a language like Finnish, where most utterances are clausal, there are plenty of other types of utterances too. On the other hand, the clause is not as good a fit for Japanese; not many utterances in Japanese conversation are clausal in the sense that syntactically they do not look at all like the clause which is found in the discussion of languages like English and in standard references in linguistics. In addition, we have recent reports from other languages based on the examination of conversational data which indicate that the clause is not at all a good fit for Nuuchahnulth (Nakayama 2002, 2013) and Indonesian (Ewing, this volume). Both of these languages highlight the potential problem of applying a unit useful for the description of one language to another language. The latter study gives an especially clear demonstration of this problem in a quantitative manner.

Given the above discovery, we would like to point out that in analyzing particular languages, we need to ask whether linguistic categories are in fact a result of our training and tradition. We often observe that the situation that we discuss is compounded by a common behavior of prematurely seeking for universals. That is, there is a tendency in the field to define a structural unit first, based on a (limited) sample of languages ('a priori'), and then search for manifestations in a range of languages. The range of languages closely studied is still limited, as is the range of genres and situations of use. And, the establishment of universals obviously has to be based on what actual speakers do, not what we think they do. 
Before we end our paper, we would like to give further discussion on the views expressed in recent articles by Ford, Fox and Thompson (2013) and Haspelmath (2010):

The findings of the present study are critically relevant to Ford, Fox and Thompson (2013) who question the usefulness of "a priori linguistic categories and linguistic units" for the analysis of talk-in-interaction as these researchers fail to see conversational participants orient to them. They suggest that "a priori linguistic categories and linguistic units" may be neither "relevant nor necessary to account for turn construction (16)", because formal descriptions are "not interactionally relevant (47)". 29

The clause is a prime example of an a priori linguistic unit, and by studying phenomena such as turn transition, joint utterance completion and incrementation originally examined by Thompson and Couper-Kuhlen (2005) along with the actual frequency of use as a set of criteria, we have been able to show that participant orientation is in fact mostly useful to identify the clause as a unit in Finnish. The identification of clauses in the sense of a structural unit similar to the English clause through participant orientation, however, turned out to be rather problematic in Japanese. The above set of criteria did not support, or was irrelevant to, 'clause'; instead it appears to work better in identifying shorter phrases consisting of the predicate with occasional overt NPs. ${ }^{30}$ In this context, it is especially noteworthy that our review of early Japanese literature also revealed that this latter type of unit was their primary focus, and a unit type similar to English clause was not recognized until the introduction to Japan of the study of English and other European languages where such a unit is clearly relevant and thus more firmly established in grammatical descriptions. These observations lead to the conclusion that the clause is perhaps not a well-established unit at least in the grammar of Japanese everyday talk, and the central status given to the clause in the discussion of Japanese appears to be an outcome of the influence from Western scholarship which is obviously based on the study of Western languages. In contrast to the early Japanese grammatical descriptions, the earliest work on Finnish grammar is focused on the clause as a unit.

Regardless, our exploration thus shows that participant orientation is in fact useful to identify unit types which are commonly employed in everyday talk in each language (clauses in Finnish and predicates with occasional overt NPs in Japanese), and this leads to our current view that Ford, Fox and Thompson's

\footnotetext{
${ }^{29}$ Even these researchers are not able to entirely do away with grammatical terms such as 'final particle' (23), and indeed they suggest that they, as well as other researchers analyzing conversation, will continue to use grammatical terminology in their future research, as they have done in the past (49).

30 Some researchers including Iwasaki (1993) and Matsumoto (2003) assume that these short utterances are also clauses on the grounds that they can be understood to express coherent conceptual units such as propositions similar to what clauses in languages like English express. Our central claim, however, is that in languages like Japanese, the expression of those conceptual units as clauses is not as grammaticized as in languages like English, as the expression of associated elements is not grammatically required.
} 
provocative claim (2013), based on a close examination of what interactants do in everyday talk like our study, is worthy of further inspection. ${ }^{31}$

At another level, our study supports a recent position taken by Haspelmath (2010: 673) that 'clause' be considered a comparative concept (not necessarily universal) which need not be valid for speakers of particular languages (not a descriptive category), but which nevertheless may be useful for crosslinguistic comparison. Our exploration of 'clause' has led to uncovering major differences between Finnish and Japanese (and Indonesian and Nuuchahnulth), which clearly demonstrates the problem of using the term to describe the unit types that we examined in the two languages. ${ }^{32}$ That is, we find that in encoding a predication, the structural fit between the traditional unit 'clause' and what is most commonly used in each language varies quite extensively in that the fit is close in languages like Finnish, English, and German but not so in languages like Japanese, Indonesian, and Nuuchahnulth. This leads to our current hypothesis that 'clause' may not be grammaticized for all languages, at least not to the same degree. On that basis, we would also like to suggest that looking for clause might not be a wise first step in trying to describe a language, especially when the language is not well understood. ${ }^{33}$

\section{References}

Auer, Peter. 2014. Sentences and their symbiotic guests. Notes on analepsis from the perspective of online syntax. Pragmatics 24 (3): 533-560.

Biber Douglas, Stig Johansson, Geoffrey Leech, Susan Conrad \& Edward Finegan. 1999. Longman Grammar of Spoken and Written English. London: Longman.

Bybee, Joan. 2010. Language, Usage and Cognition. Cambridge: Cambridge University Press.

\footnotetext{
31 We discuss this more in detail in the introductory article of this volume.

32 Haspelmath (2010b: 697) defines the comparative concept clause as "an expression that contains one predicate and potentially at least some of its arguments and that can be independently negated" (see our introductory paper in this volume for further discussion of Haspelmath). This definition, carefully worded to represent a concept for language comparison, not a universal category, is quite inclusive and can actually capture not only the utterance types in Finnish but also some in Japanese we examined in this paper. It is problematic in the sense that a crude application of the definition leads analysts (especially those who are in quests for universals) to miss significant structural differences in everyday interaction data of these languages which we discussed in the present paper, resulting in premature implications of universals which the current paper is warning against.

33 An anonymous reviewer rightly questions our method of separating grammar and participant orientation. As one way to look at grammar, we did that, but our assumption was clearly that they can be separable. We appreciate this reviewer's pointing out the possibility that the representation of real speakers might involve the two in an inseparable way so that trying to look just at grammatical units such as clause as we did might be problematic.
} 
Chafe, Wallace. 1994. Discourse, Consciousness and Time. The Flow and Displacement of Conscious Experience in Speaking and Writing. Chicago: The University of Chicago Press.

Chomsky, Noam. 1957. Syntactic Structures. London: Mouton.

Clancy M. Patricia. 1980. Referential choice in English and Japanese narrative discourse. In Wallace L. Chafe (ed.), The pear stories: Cognitive, cultural, and linguistic aspects of narrative production. Norwood: Ablex.

Comrie, Bernard. 1989. Language Universals and Linguistic Typology. Chicago: The University of Chicago Press.

Couper-Kuhlen, Elizabeth. 2014. What does grammar tell us about action. Pragmatics 24 (3): 623-648.

Croft, William. 1990. Typology and universals. Cambridge: Cambridge University Press.

Crystal, David. 1998. A Dictionary of Linguistics and Phonetics. Oxford: Blackwell.

Du Bois, John W. 1987. The Discourse Basis of Ergativity. Language 63: 805-855.

Du Bois, John W. 2014. Towards a Dialogic Syntax. Cognitive Linguistics 25(3): 359-410.

Etelämäki, Marja, Markku Haakana \& Mia Halonen. 2013. Keskustelukumppanin kehuminen suomalaisessa keskustelussa. [Complimenting in Finnish conversation.] Virittäjä 117: 461-494.

Ford, Cecilia E., Barbara A. Fox \& Sandra A. Thompson. 2002. The Language of Turn and Sequence. New York: Oxford University Press.

Ford, Cecilia E., Barbara A. Fox \& Sandra A. Thompson. 2013. Units and/ or action trajectories? The language of grammatical categories and the language of social action. In Beatrice Szczepek Reed and Geoffrey Raymond (eds) Units of Talk -Units of Action. Amsterdam: Benjamins. Pp. 13-56.

Fox, Barbara A. 2007. Principles shaping grammatical practices: An exploration. Discourse Studies 9: 299-318.

Fromkin, V., Rodman, R., \& Hyams, N. (2011). An Introduction to Language (9th ed.). Boston, USA: Cengage Learning Wadsworth.

Givón, Talmy. 1984. Syntax. A functional-typological introduction. Amsterdam: Benjamins. 
Goodwin, Charles. 1979. The interactive construction of a sentence in natural conversation. In George Psathas (ed.) Everyday Language: Studies in Ethnomethodology. New York: Irvington Publishers. 97-121.

Goodwin, Charles. 1981. Conversational Organization: Interaction between Speakers and Hearers. London, Academic Press.

Greenberg, Joseph, ed.1978. Universals of Human Language. Stanford: Stanford University Press.

Hakulinen, Auli \& Fred Karlsson. 1979. Nykysuomen lauseoppia. Helsinki: Suomalaisen Kirjallisuuden Seura.

Hakulinen, Auli, Maria Vilkuna, Riitta Korhonen, Vesa Koivisto, Tarja Riitta Heinonen \& Irja Alho. 2004. Iso suomen kielioppi. Helsinki: Suomalaisen Kirjallisuuden Seura.

Hakulinen, Auli \& Marja-Leena Sorjonen. 2009. Designing utterances for action: Verb repeat responses to assessments. In Markku Haakana, Minna Laakso \& Jan Lindström (eds) 2010. Talk in Interaction. Comparative Dimensions. Helsinki: Suomalaisen Kirjallisuuden Seura. 124-151.

Haspelmath, Martin. 2010a. Comparative concepts and descriptive categories in crosslinguistic studies. Language 86(3): 663-687.

Haspelmath, Martin. 2010b. The interplay between comparative concepts and descriptive categories (Reply to Newmeyer). Language 86(3): 696-699.

Hayashi, Makoto. 1999. Where grammar and interaction meet: A study of coparticipant completion in Japanese conversation. Human Studies 22:475-499.

Hayashi, Makoto. 2003. Joint Utterance Construction in Japanese Conversation. Amsterdam/ Philadelphia: John Benjamins.

Helasvuo, Marja-Liisa. 2001. Syntax in the making: The emergence of syntactic units in Finnish conversational discourse. Studies in Discourse and Grammar 9. Amsterdam: John Benjamins.

Hida, Yoshifumi. 2007. Bun. In Yoshihide Endo, Masanobu Kato, Takeyoshi Sato, Kiyoto Hachiya, and Tomiyoshi Maeda (eds.). Nihongogaku Kenkyu Jiten. [Encyclopedia of Research in Japanese Linguistics] Tokyo: Meiji Shoin.

Hinds, John. 1980. Japanese conversation, discourse structure, and ellipsis. Discourse Processes, 263-286.

Hinds, John. 1982. Japanese conversational structures. Lingua 57: 2-4, pp. 301326. 
Hopper, Paul J. and Elizabeth Closs Traugott. 2003. Grammaticalization. Cambridge University Press.

Hoye, Masako. 2008. Exploration of the notion of subject in Japanese. Ph.D. dissertation. University of Colorado.

Ikola, Osmo, Ulla Palomäki \& Anna-Kaisa Koitto. 1989. Suomen murteiden lauseoppia ja tekstikielioppia. Helsinki: Suomalaisen Kirjallisuuden Seura.

Iwasaki, Shoichi. 1993. The structure of the Intonation Unit in Japanese. Japanese/ Korean Linguistics. 3: 39-53, Stanford: CSLI.

Iwasaki, Shoichi 2014. Grammar of the Internal Expressive Sentences in Japanese: Observations and Explorations. In Kaori Kabata and Tsuyoshi Ono (eds.) Usage-based Approaches to Japanese Grammar. Amsterdam: John Benjamins, 55-83.

Jahnsson, Adolf Waldemar. 1871. Finska språkets satslära. Helsinki.

Kärkkäinen, Elise \& Tiina Keisanen. 2012. Linguistic and embodied formats for making (concrete) offers. Discourse Studies 14(5): 1-25

Kinsui, Satoshi. 1997. Kokubunpoo [Japanese grammar]. In Takashi Masuoka, Yoshio Nitta, Takao Gunji and Satoshi Kinsui (eds.). Bunpoo. p. 119-157. Tokyo: Iwanami Shoten.

Kuno, Susumu. 1973. The Structure of the Japanese Language. Cambridge, MA; MIT Press.

Laakso, Minna \& Marja-Leena Sorjonen. 2010. Cut-off or particle. Devices for initiating self-repair in conversation. Journal of Pragmatics 42: 1151-1172.

Laury, Ritva. 2018. The Finnish verb repeat response: Elliptical 'fragment', fixed expression, or independent unit? Journal of Pragmatics 123: 139-150.

Lerner, Gene. 1991. On the syntax of sentences in progress. Language in Society 20: 441-458.

Linell, Per. 2005. The Written Language Bias in Linguistics. Its Nature, Origins and Transformations. London: Routledge.

Linell, Per. 2009. Rethinking Language, Mind and World Dialogically. Interactional and contextual theories of human sense-making. Charlotte, NC: Information Age Publishing.

Linell, Per. 2013 The dynamics of incrementation in utterance-building: Processes and resources. In Beatrice Szczepek Reed \& Geoffrey Raymond (eds.), Units of Talk - Units of Action. Amsterdam: John Benjamins. 57-89. 
Martin, Samuel Elmo. 2004 (1975). A Reference Grammar of Japanese. Honolulu: University of Hawaii Press (New Haven, CT: Yale University Press).

Masuoka, Takashi, and Yukinori Takubo. 1992. Kiso Nihongo Bunpoo: Kaiteiban [Basic Japanese grammar: A revised edition]. Tokyo: Kuroshio Publishers.

Matsumoto, Kazuko. 2003. Intonation Units in Japanese Conversation: Syntactic, Informational and Functional Structures. Amsterdam: John Benjamins.

Matthews, P.H. 2014. (Online version) The Concise Oxford Dictionary of Linguistics (3 ed.) Oxford University Press.

Maynard, Senko K. 1989. Japanese Conversation: Self-contextualization Through Structure and Interactional Management. Norwood: Ablex.

Maynard, Senko K. 1990. Conversation Management in Contrast: Listener Response in Japanese and American English. Journal of Pragmatics 14:397-412.

Minami, Fujio. 1974. Gendai nihongo no koozoo [The Structure of Modern Japanese]. Tokyo: Taishukan.

Nakayama, Toshihide. 2002. Nuuchahnulth (Nootka) Morphosyntax. UC Publications in Linguistics 134. Oakland: University of California Press.

Nakayama, Toshihide. 2013. Emergent nature of linguistic units. Workshop 'Linguistic and interactional units in everyday speech: Cross-linguistic perspective', University of Alberta.

Narrog, Heiko. 2009. Modality in Japanese: The Layered Structure of the Clause and Hierarchies of Functional Categories. Amsterdam: John Benjamins.

Nitta, Yoshio. 2007 Ku. In Yoshihide, Endo, Masanobu, Kato, Takeyoshi Sato, Kiyoto Hachiya, Tomiyoshi, Maeda (eds.). Nihongogaku Kenkyu Jiten [Encyclopedia of Research in Japanese Linguistics] Tokyo: Meiji Shoin.

Okamoto, Shigeko. 1985. Ellipsis in Japanese Discourse. Ph.D. dissertation, University of California, Berkeley.

Ono, Tsuyoshi \& Elizabeth Couper-Kuhlen 2007. Incrementing in conversation. A comparison of practices in English, German and Japanese. Pragmatics 17 (4): 513-552.

Ono, Tsuyoshi and Ryoko Suzuki. 2018. The use of frequent verbs as reactive tokens in Japanese everyday talk: Formulaicity, florescence, and grammaticization. Journal of Pragmatics 123: 209-219. 
Ono, Tsuyoshi and Sandra A. Thompson 1997. Deconstructing "Zero Anaphora" in Japanese. Proceedings of the Twenty-Third Annual Meeting of the Berkeley Linguistics Society: General Session and Parasession on Pragmatics and Grammatical Structure, pp. 481-491.

Ono, Tsuyoshi, Sandra A. Thompson and Ryoko Suzuki. 2000. The Pragmatic Nature of the So-called Subject Marker ga in Japanese: Evidence from Conversation. Discourse Studies, 2(1):55-84.

Otsuki, Fumihiko. 1897. Koonihonbunten. Tokyo: Yoshikawa Hanshichi.

Payne, Thomas. 1997. Describing Morphosyntax: A guide for field linguists. Cambridge: Cambridge University Press.

Setälä, Eemil Nestor. 1926 [1880]. Suomen kielen lauseoppi. Helsinki: Otava.

Shimojo, Mitsuaki. 2005. Argument Encoding in Japanese Conversation. New York: Palgrave Macmillan.

Shopen, Timothy. 2007. Language Typology and Syntactic Description, Second Edition. Vol. I. Clause Structure. Cambridge: Cambridge University Press.

Sorjonen, Marja-Leena \& Minna Laakso. 2005. Katko vai eiku. Itselkorjauksen aloitustavat ja vuorvaikutustehtävät. Virittäjä 109: 244-271.

Suzuki, Ryoko. 2016. Kaiwa ni okeru dooshi yurai no han'noo Hyogen: Aru to iru o chuushin ni [Reactive expressions of verb origin: with focus on aru and iru]. In Yoko Fujii and Hiroko Takanashi (eds.), Komyunikeeshon no dainamizumu: Shizen hatsuwa deeta kara [Dynamics of Communication: Analyses of Natural Discourse]. Tokyo: Hituzi Shobo.

Teramura, Hideo. 1982. Nihongo no Shintakusu to imi [Syntax and semantics of Japanese], vol.1. Tokyo: Kuroshio Publishers.

Thompson, Sandra A. \& Elizabeth Couper-Kuhlen. 2005. The clause as a locus of grammar and interaction. Discourse Studies 7: 481-505.

Thompson, Sandra A., Barbara A. Fox \& Elizabeth Couper-Kuhlen. 2015.

Grammar in Everyday Talk: Building responsive actions. Cambridge: Cambridge University Press.

Trask, Robert, L. 1997. A student's dictionary of language and linguistics.

Tuomikoski, Risto. 1969. Lauseiden ja virkkeiden terminologiasta. [Clause and sentence terminology in Finnish Grammars] Virittäjä 73 (1): 62-68

Vatanen, Anna. 2014. Responding in overlap. Agency, epistemicity and social action in conversation. PhD thesis. University of Helsinki, Department of Finnish, Finno-Ugrian and Scandinavian Studies. 
Watanabe, Minoru. 1953. Jojutsu to chinjutsu: Jutsugo bunsetsu no koozoo

[Predication and modality: The structure of predicates]. Kokugogaku. 13-14: 2034.

Watanabe, Minoru. 1974. Kokugo Bunpooron [A Study of Japanese Grammar]. Tokyo: Kasama Shoin.

Yamada, Yoshio. 1924. Nihon Bunpoo Koogi [Lectures on Japanese Grammar], 3 $3^{\text {rd }}$ ed. Tokyo: Tokyo Hobunkan.

Yamada, Yoshio. 1978. Ku. Published in Nihon Bunpougaku Gairon (1936). Reprinted in Shiro Hattori, Suzumu Oono, Atsuyoshi Sakakura and Akira Matsumura (eds.). Nihon no gengogaku 3 Bunpoo I (Linguistics in Japan vol. 3 Grammar I) 73-96. Tokyo: Taishukan. 